\title{
Chemistry of $\mathrm{Milk}$
}

$\mathrm{R}^{\mathrm{r}}$ ECENT work on the chemistry of milk was discussed at a joint session between Sections B (Chemistry) and M (Agriculture) on September 11 at the Aberdeen meeting of the British Association. For convenience the discussion was divided into two parts : (1) a consideration of milk, normal and abnormal, from the analytical point of view; and (2) a survey of recent work on some of the more important organic constituents of milk, namely, casein, milk fat and vitamins.

Prof. H. D. Kay (Reading), in a general introductory paper, pointed out that despite their inherent academic interest and their enormous importance in human nutrition, in agriculture and in industry, it is only comparatively recently that the chemistry and physiology of milk secretion have become subjects of serious study and research. Our fundamental knowledge of lactation from the chemical and biochemical point of view is still surprisingly meagre. To mention a few only of the many questions on which little effective light has as yet been thrown, we are almost entirely ignorant as to what factors control the chemical quality of milk as secreted by the cow; we do not know why the main protein of milk is a peculiar and unusual one-a phosphoprotein-or why milk fat has its very peculiar composition with its high percentage of volatile fatty acids, or why the sugar in milk is lactose and not some more common sugar, or why citric acid is present in appreciable quantities in fresh milk. Have these peculiarities arisen during long ages of evolution to meet specific needs of the young suckling, or are they the result of some secretory necessity of the mammary gland? No answer to these and other fundamental questions, many of which are both scientifically fascinating and economically important, can be attempted until a wider and more precise knowledge of the chemistry of milk is available.

In the analytical part of the discussion, Dr. J. F. Tocher (Aberdeen) considered the composition of milk in relationship to the existing regulations, designed to safeguard the consumer against having his milk spuriously diluted, and described methods used for determining, from the predicted and observed values of certain of the non-fatty solids in the milk, whether or not a sample of milk has been 'watered'. He also described critically his recent work on the determination of the freezing point of milk, the range of variation of which, over a large number of samples of fresh milk, is known to be small, but which according to his own findings is rather larger than the usually accepted range. His variations are from $-0.50^{\circ}$ to $-0.56^{\circ} \mathrm{C}$., and he finds that the mean value of the freezing point of the milk of individual cows is not the same from one herd to another. He advocated caution in making any statement, based on cryoscopic determinations alone, as to the exact quantitative extent to which a given sample of milk has been adulterated with water.

Dr. W. L. Davies (Shinfield) dealt with the limits between which cow's milk may vary in analytical composition and still be considered normal. In abnormal milk the percentage of specific milk constituents, particularly casein and lactose, is usually low. If it is assumed that normal milk contains 76 per cent of its total nitrogen as casein nitrogen, then abnormal milk may be regarded as normal milk plus a diluting fraction, and the nitrogen distribution, chloride content, etc., of the diluting fraction can in any given case be calculated. On making this calculation it is found that the diluting fraction is not far removed in composition from blood serum or from certain types of cedema fluid. These findings appear to put the changes known to occur in abnormal milk on to a more intelligible basis.

A short but lively discussion on these two papers was opened by Capt. John Golding (Shinfield). Capt. Golding believes that Dr. Tocher's range of variation in freezing points is much too great for fresh samples of genuine milk, and quoted a very extensive series of determinations of his own, where, with genuine milk of the most abnormal composition, the freezing point was so constant from one milk to another as to be scarcely ever outside the small experimental error of his method. Never under any conditions has he himself come across a fresh, genuine milk with a freezing point outside the range $-0.537^{\circ}$ to $-0 \cdot 570^{\circ}$ for mixed milks : 99 per cent of these determinations fall between $-0.545^{\circ}$ and $-0.555^{\circ}$. Mr. A. L. Bacharach (London) emphasised that the long contest between analyst and adulterator is by no means rendered one-sided by the increasing use of the cryoscopic test, despite the remarkable constancy of the freezing point in fresh milk. By careful sophistication with 'solutions of electrolytes', the scientific adulterator can evade even the freezing point test. Sir Robert Robertson (London) mentioned the difficulties that arise if milk for a freezing point test is received after some souring has taken place. It is, however, possible, even with milk in which bacterial changes are already advanced, to compute with some accuracy, from the results of a careful analysis of the milk, what the original composition would have been, and thus give an opinion as to whether the freezing point claimed for the milk in its original fresh condition is likely to be correct.

The second half of the discussion was opened by Dr. K. Linderstrøm-Lang (Copenhagen), who described his work on the fractionation of casein into several different protein components which show marked differences in their content of phosphorus, tyrosine, tryptophane, histidine and alanine, as also in their specific rotation and base-binding capacity. It appears from this work that casein should be regarded not as a single protein of very large molecular weight but as a mixture of smaller protein units, with certain chemical similarities, and possibly very loosely linked together. It forms a co-precipita tion system which is, however, fairly readily resolvable by simple physical methods.

Dr. Linderstrøm-Lang also dealt with recent work on the chemical make-up of casein, particularly the form in which phosphoric acid is combined with the rest of the protein molecule. The recent isolation by Lipmann of a new amino acid, phosphoserine, from casein hydrolysates demonstrates that some at least of the phosphorus in casein itself is present linked to serine. From other recent work of Levene and Hill, it may be concluded that a glutamic acid molecule is also a near neighbour of phosphoserine in the casein molecule. Investigations of the rate of splitting off of phosphorus as phosphoric acid suggest that all the phosphorus in casein is bound in a similar way, which is almost certainly an ester linkage to hydroxyamino acids, but all the phosphorus is not necessarily bound to the same hydroxyamino acid. 
The peculiar constitution of milk fat is emphasised by the recent work which was reported by Prof. T. P. Hilditch (Liverpool). It has been known for some time that there is a large proportion of fatty acids of relatively low molecular weight, from butyric acid upward, in milk fat. Whilst on the whole there is a remarkable constancy in the proportions of the various fatty acids in milk fat from cows in countries so far apart as England, New Zealand and India, there are minor variations depending in part on the diet. Stall-fed cows produce a more saturated butter fat than cows at pasture, and the unsaturation is increased shortly after the cows go out to grass in spring. As the unsaturation increases, the quantity of low-molecular fatty acids diminishes. Increasing age of the cow appears to increase the proportion of oleic acid slightly at the expense of palmitic acid. A diet in which fat containing fatty acids of a particular or unusual type is present influences the composition of the butter fat by slightly increasing the content in the butter of such characteristic fatty acids, and correspondingly diminishing the content of certain of the fatty acids present in normal butter. The influence of cod liver oil is particularly marked in diminishing the amount of volatile fatty acids in the butter.

The comparative heterogeneity of the triglycerides present in butter contributes very considerably to the important economic quality of 'spreadability' and to the relatively low melting point of butter fat.

Dr. S. K. Kon (Shinfield) contributed the last paper. He described work extending over three complete years on the changes in vitamin content of milk throughout the year. Winter butter from cows on the usual winter rations has been clearly shown to have a smaller vitamin content than summer butter from the same cows. Direct photometric measurement of the vitamin A sensu stricto, and of the carotene content of butters in relation to their total vitamin A activity as estimated biologically, has yielded the interesting finding that the biological growth-promoting power of true vitamin $\mathbf{A}$ of butter is 5-7 times that of an equal weight of butter carotene. Experiments were described which showed that the antirachitic effect of butter is due only in part to the classical vitamin D. There is another factor in butter which, unlike irradiated ergosterol, is easily inactivated during saponification, but which is effective in the prevention or cure of experimental rickets in rats. The reversible oxidation of vitamin $\mathrm{C}$ in milk in the presence of light was described. Ordinary daylight even through glass bottles is effective in accelerating this oxidation, which appears to be less and less reversible as the time of exposure of the milk to the light increases.

\section{The Frontiers of Science}

CCIENCE, as an advance of organised knowledge $\checkmark$ into Nature, is constantly driving its frontiers into the region of the unknown and the unexplained. The record of that conquest is as dramatic and important as any that historians have to analyse and describe. But the frontiers of science are not merely abstract ones in the realm of thought; historically, they have also moved geographically into new worlds, and new influences have penetrated into systems of organised knowledge by geographical routes which are still traceable. Within the system of science also, the lines between various depart. ments have been constantly moving and classifications of knowledge transmuted. Historians of science are largely occupied with this problem of the external and internal boundaries of science, and their attempts to map out the development is of great importance as a contribution towards science's understanding of itself.

The increasing self-consciousness of science, shown by the philosophic preoccupations of physicists and biologists and the development of a social conscience by the British Association, stimulates its historical memory. After congresses in Paris in 1928 and in London in 1931, a third international congress under the auspices of the International Academy of the History of Science was held this year in Portugal on September 30-October 6, under the presidency of Dr. Fernando de Vasconcelos. Besides a distinguished group of Portuguese scholars, representatives from, among others, Belgium, Czechoslovakia, Egypt, France, Great Britain, Italy, Morocco, Norway, Roumania, Spain and the United States were present. The absence of German representatives was conspicuous.

The obligations of science and in particular of historians of science were emphasised by Dr. George Sarton of Harvard in an inaugural address. He directed attention to the dangers that threaten the independence of science in many countries to-day, and protested against the prostitution of the history of science to serve the narrow ends of national or political propaganda. He believes that in the true history of science there is a firm basis for international understanding and a potent method of humanising the sciences and more intimately relating the interests of humanists and workers in natural science.

These general questions were considered further in a discussion on the unity of science in which Dr. Henriques of Rome urged that it is one of the important tasks of the history of science to emphasise the relative and temporary nature of the subdivisions of the sciences, often artificially perpetuated by administrative and teaching habits, and to insist always that the necessarily specialised studies of experts should be approached from, or at least related to, the concept of the unity of science. Although the idea of unity raises problems of definition of a metaphysical character, the practical bearing of the suggestion for the teaching of the history of science was recognised by the decision to appoint a committee of the Academy under the chairmanship of Dr. A. Reymond of Lausanne to investigate and report on a programme of international collaboration in the teaching of the history of science.

The international character of science, and the fictitiousness of the boundaries between the various branches of sciences, were shown by the papers presented at the sectional meetings. The general theme was the geographical expansion of scientific knowledge, the function of the various sciences in shaping the movement of European expansion in the age of the discoveries, and the diffusion of knowledge within Western culture. A series of papers by Portuguese representatives showed that the fundamental work of Joachim Bensaude on early Portuguese astronomy has been followed by similar studies in other fields. Perhaps the most important of these papers were 